14

\title{
Получение и исследование растворимых функционализированных полианилинов
}

\author{
(С) Ю.Н. Биглова ${ }^{1}$, Р.Б. Салихов ${ }^{1, \uparrow}$, И.Б. Абдрахманов ${ }^{2}$, Т.Р. Салихов ${ }^{1}$, И.Н. Сафаргалин ${ }^{1}$, А.Г. Мустафин $^{1,2}$ \\ ${ }^{1}$ Башкирский государственный университет, \\ Уфра, Россия \\ ${ }^{2}$ Уфримский институт химии РАН, \\ Уфра, Россия \\ IE-mail: salikhovrb@yandex.ru
}

(Поступила в Редакцию 14 ноября 2016 г.)

\begin{abstract}
На основе функционализированных мономерных анилинов впервые синтезированы и охарактеризованы растворимые электронодонорные проводящие (со)полимеры. Показана хорошая корреляция результатов при изучении электрохимических свойств производных полианилина методами циклической вольтамперометрии и на основании температурной зависимости проводимости. Полимер на основе 2-(1-метил-2-бутен-1-ил)анилина имеет наименьший энергетический уровень верхней занятой молекулярной орбитали, что определяет перспективность его применения в качестве донора в активном слое при конструировании органических солнечных батарей.
\end{abstract}

Работа выполнена при финансовой поддержке Российского фонда фундаментальных исследований в рамках контракта № 14-02-97008.

DOI: 10.21883/FTT.2017.06.44497.412

\section{1. Введение}

Полианилин (ПАНИ) с момента обнаружения его полупроводниковых свойств превратился в перспективный электропроводящий полимер (открытие и исследование таких высокомолекулярных соединений отмечено Нобелевской премией по химии в 2000-м году). От других проводящих полимеров ПАНИ выгодно отличает устойчивость к воздействию влаги и кислорода воздуха, его синтез достаточно прост, а исходный мономер - дешевый и доступный. Как и многие обладающие свойствами полупроводников высокомолекулярные соединения (полиацетилен, пилитиофен, полипиррол и др.), ПАНИ может находиться в разных окисленных состояниях и давать соответствующий отклик на внешнее воздействие. Он меняет свою электропроводность, магнитные свойства, цвет и плотность, гидрофильность - гидрофобность, проницаемость для газов и жидкостей. ПАНИ обладает контролируемой электронной проводимостью $10^{-10}-10^{1} \mathrm{~S} / \mathrm{cm}$ в сочетании с ионной проводимостью, окислительно-восстановительной активностью, нелинейными оптическими свойствами и парамагнетизмом. Благодаря уникальному комплексу свойств и высокой стабильности, ПАНИ первым среди электропроводящих высокомолекулярных соединений стал использоваться на практике. Например, при разработке устройств альтернативной энергетики - топливных элементов [1]. Успешно ПАНИ применяется и для экранирования электромагнитного излучения: высокий уровень поглощения в диапазоне $10-100 \mathrm{GHz}$ имеют и полимерные пленки на пористых носителях, и композиты ПАНИ с металлическими или магнитными наполнителями [2].
Разработка нового поколения сенсорных устройств связана в основном с двумя электропроводящими высокомолекулярными соединениями - полианилином и полипирролом, которые употребляют в высокоселективных устройствах для диагностики смесей газов и жидкостей под названием „электронный нос““ и „электронный язык“ [3-6]. Чрезвычайно перспективно биомедицинское направление исследования ПАНИ. Показана применимость в качестве биосовместимого электрода: электрические сигналы, подаваемые на нанесенный in vivo полимерный слой, способствуют ускорению регенерации тканей $[7,8]$. Спектр уже имеющихся и потенциально возможных применений ПАНИ очень широк, тем не менее существуют серьезные проблемы, сдерживающие его практическое использование. Во-первых, это синтез ПАНИ с воспроизводимыми свойствами. Образцы полимера могут содержать разнообразные продукты окисления анилина, демонстрирующие отличающуюся в десятки раз электропроводность. Отличаются они по спектральным, магнитным характеристикам, они могут иметь принципиально различную морфологию. Обозначенная неопределенность приводит к неоднозначным результатам и требует основательного исследования процесса окислительной полимеризации анилина.

Вторая проблема связана с созданием материалов для практического применения. Как недостаток полимера следует отметить тот факт, что он не плавится и практически нерастворим в типовых органических растворителях. Поэтому ПАНИ относится к категории неперерабатываемых материалов. Более того, полимер представляет собой порошок, не обладающий адгезией к другим материалам. 
Ввиду сказанного выше, очевидно, что синтез является ключевым звеном не только получения ПАНИ, но и композиционных материалов на его основе. Несмотря на кажущуюся простоту, окислительная полимеризация анилина - сложная многостадийная реакция. Обычная процедура химического синтеза ПАНИ включает окислительную полимеризацию мономера в водном растворе неорганической кислоты $[9,10]$. В этих условиях происходит образование нерастворимого в большинстве доступных органических растворителей неплавкого порошка $[11,12]$. Для исключения перечисленных недостатков ПАНИ различным образом модифицируют. Альтернативным вариантом оптимизации эксплуатационных параметров полимера является функционализация не целевого продукта, а исходного мономера. Так, введение в полимеризационный процесс $o$-толуидина, $o$-анизидина (вместо анилина) приводит к выделению растворимых в органических растворителях высокомолекулярных соединений. Далее с участием гомополимера на основе $o$-толуидина могут быть сконструированы электрохромные и фотогальванические устройства [13]. Есть примеры, когда при осуществлении электрохимической полимеризации $o$-толуидина в качестве электролита использовали различные растворы кислот: авторы [14] серную кислоту, $n$-толуолсульфоновую кислоту, сульфаминовую кислоту и сульфосалициловую кислоту, [15] серную и хлорную. Сопоставительный анализ синтезированных веществ показал, что максимальную электропроводность имеет выделенный с участием сульфокислот полимер, растворимый в большинстве типовых растворителей. В ряде работ предлагается способ получения высокомолекулярных соединений, характеризующихся высокой электропроводностью и хорошей растворимостью, путем варьирования соотношения сомономеров (электрохимическая полимеризация). При этом синтезированы сополимеры на основе $о$-анизидина и $o$-толуидина [16]. Отмечается, что наиболее стабильные пленки получаются из сополимера, в составе которого пиррола более $50 \%$ по отношению к о-толуидину.

Как в России, так и за рубежом научные коллективы ученых решают актуальные задачи: 1) разработка контролируемых методов синтеза ПАНИ, ведущих к получению полимерных материалов с заданной морфологией и свойствами; 2) вовлечение в полимеризационный процесс функционализированных анилинов для повышения эксплуатационных характеристик продукта; 3) расширение ассортимента электропроводящих высокомолекулярных соединений, прежде всего, с использованием функционализированного анилина для выявления наиболее эффективных электроактивных представителей. В связи со сказанным выше, цель настоящей работы выявление наиболее эффективных представителей и расширение ассортимента электропроводящих высокомолекулярных соединений, прежде всего, с использованием функционализированного анилина, и исследование электрофизических и физико-химических свойств целевых продуктов.

\section{2. Экспериментальная часть}

2.1. Материалы. Используемые в работе коммерчески доступные реагенты и растворители, такие как персульфат аммония, o-толуидин, $о$-дихлорбензол, тетра (н-бутил)аммоний гексафторфосфат $\left(\mathrm{Bu}_{4} \mathrm{NPF}_{6}\right)$, ферроцен, получали из фирмы Aldrich и использовали без дальнейшей очистки.

Ацетонитрил, хлороформ после очистки общепринятыми методами $[17,18]$ имели характеристики, соответствующие литературным данным.

В качестве объектов исследования выбраны производные анилина, синтезированные и охарактеризованные в Уфимском институте химии РАН. Алкильное производное анилина - 2-(1-метил-2-бутен-1-ил)анилин (А на рис. 1) - синтезировали по методике [19] и охарактеризовывали с привлечением спектроскопии и спектрометрии.

2.2. Получение (со)полимеров. Поли-2-(1-метил-2-бутен-1-ил)анилин (1) получали методом окислительной полимеризации путем смешивания при $0^{\circ} \mathrm{C}$ равных объемов растворов 2-(1-метил-2-бутен-1-ил)анилина $(\mathrm{A})(0.2 \mathrm{~mol})$ в соляной кислоте $(0.2 \mathrm{~mol})$ и персульфата аммония $(0.25 \mathrm{~mol})$ в соляной кислоте $(0.2 \mathrm{~mol})$. В течение $60 \mathrm{~min}$ в реакционной колбе протекала экзотермическая реакция, сопровождавшаяся изменением окраски реагирующей массы и выпадением обильного черно-зеленого осадка полимера. Побочные продукты синтеза, сульфат аммония и серная кислота, а также небольшие количества олигомеров модифицированного анилина удалялись многократным промыванием осадка последовательно в дистиллированной воде, ацетонотриле и метаноле. Полученный фильтрат высушивался в вакууме при комнатной температуре. Выход полимера составлял $\sim 85 \%$.

Сополимер 2 синтезировали путем смешивания при $0^{\circ} \mathrm{C}$ растворов 2-(1-метил-2-бутен-1-ил)анилина (А) $(0.15 \mathrm{~mol})$ и $о$-толуидина $(0.05 \mathrm{~mol})$ в соляной кислоте $(0.2 \mathrm{~mol})$, персульфата аммония $(0.25 \mathrm{~mol})$ в воде. Продукты реакции обрабатывали по процедуре, описанной выше для полимера 1. Выход сополимера составлял $\sim 80 \%$.

Сополимер 3 синтезировали аналогично сополимеру 2, соотношения исходных веществ составили 2-(1-метил-2-бутен-1-ил)анилина $(0.1 \mathrm{~mol})$ и $о$-толуидина $(0.1 \mathrm{~mol})$. Продукты реакции обрабатывали как описано выше. Выход сополимера составлял $\sim 80 \%$.

Сополимер 4 синтезировали аналогично сополимеру 3 , соотношения исходных веществ составили 2-(1-метил-2-бутен-1-ил)анилина $(0.05 \mathrm{~mol}) \quad$ и $\quad$-толуидина $(0.15 \mathrm{~mol})$, продукты реакции обрабатывали как описано выше. Выход сополимера составлял $~ 80 \%$.

2.3. Методики исследования. Измерение циклической вольтамперометрии (ЦВА) проводили в инертной атмосфере при комнатной температуре, растворяя производные полианилинов в $о$-дихлорбензоле с образованием растворов с концентрацией $10^{-3} \mathrm{~mol} / \mathrm{L}$ на потенциостате-гальваностате P-30JM Elins в трехэлектродной 


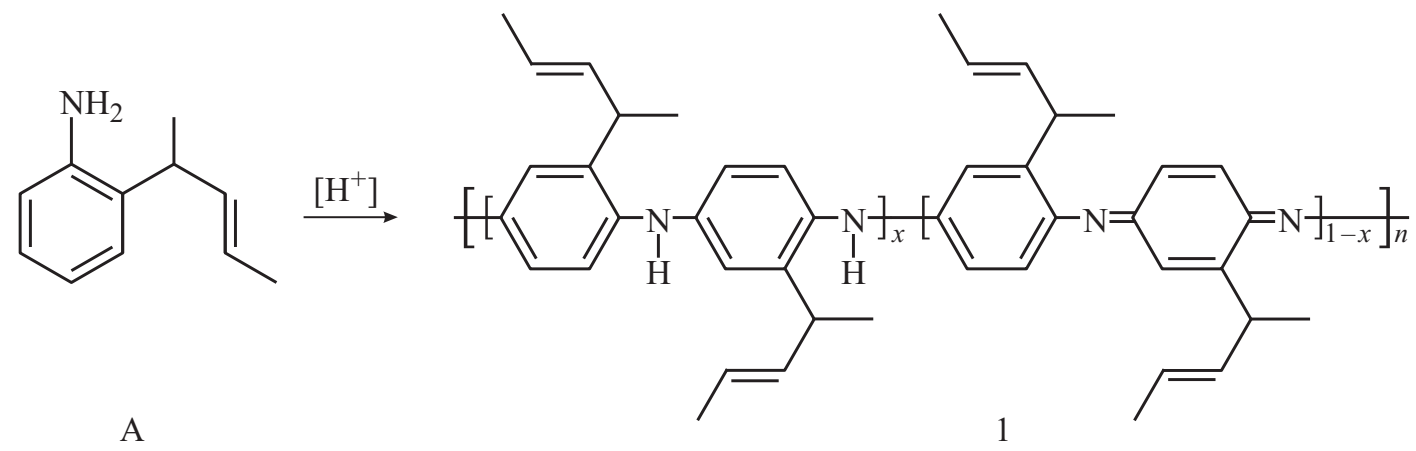

Рис. 1. Схема окисления анилина.

ячейке. Последняя состояла из рабочего стеклоуглеродного электрода $\left(5 \mathrm{~mm}^{2}\right)$, противоположного платинового электрода и $\mathrm{Ag} / \mathrm{Ag}^{+}$(0.01 mol в ацетонитриле) электрода сравнения. Скорость сканирования $50 \mathrm{mV} / \mathrm{s}$. Раствор $0.1 \mathrm{~mol} \mathrm{Bu}_{4} \mathrm{NPF}_{6}$ в ацетонитриле использовали в качестве фонового электролита. В качестве внутреннего стандарта для регистрации ЦВА использовали ферроцен.

Изготовление образцов выполняли по следующему алгоритму. Сначала осуществляли напыление электродов. Алюминиевые электроды наносились методом термического напыления в вакуумной камере на установке ВУП 5М. В качестве подложек использовали предметные стекла для микроскопических исследований с максимальной шероховатостью не более $15 \mathrm{~nm}$. При напылении оставляли зазор между электродами, равный $1 \mathrm{~mm}$, в который наносили исследуемую полимерную пленку.

На основе синтезированных полимерных производных изготавливали пленки. Для получения тонких пленок использовали раствор в хлороформе с массовой концентрацией полимерных производных 5-10\%. Нанесение полимерной пленки производили с помощью введения капли раствора мерной пипеткой на зазор между электродами с последующим центрифугированием на установке Centrifuge CM-6М. Скорость вращения центрифуги находилась в пределах 2000-2500 rpm.

Исследование зависимости сопротивления образцов от температуры в интервале 300-450 K проводили в установке, которая состоит из специальной печи с нихромовой проволокой для нагрева пленок, силового трансформатора, с помощью которого регулировалась предельная температура нагрева, цифрового мультиметpa APPA $107 \mathrm{~N}$ для измерения температуры печи и тераомметр АКИП-8602 (2500 V) для измерения сопротивления образцов.

Для проведения термогравиметрического анализа полимеров применяли прибор TGA/DSC-1 (фирмы „MettlerToledo“). Навеску исследуемого образца (5-10 mg) помещали в тигель из оксида алюминия объемом $70 \mu \mathrm{L}$. Измерения проводили в динамическом режиме в интервале температур от 25 до $600^{\circ} \mathrm{C}$ при скорости нагрева $5^{\circ} \mathrm{C} / \mathrm{min}$, атмосфера - воздух. Обработку результатов осуществляли с помощью персонального компьютера. На экран компьютера выводилась кривая в виде функции величины массы образца от температуры (кривая ТГ), а также кривая ДСК, характеризующая тепловые эффекты, происходящие при деструкции полимера. Из кривой ТГ по величине массы образца определяли значения температур $T_{\mathrm{H}}, T_{1}$, соответствующие началу разложения полимера, а также разложению его на $1 \%$ соответственно. По максимумам на кривой, производной от кривой ТГ (кривая ДТГ), определяли температуру $T_{\mathrm{m}}$, при которой достигается максимальная скорость деструкции.

\section{3. Результаты и обсуждение}

Имея ввиду, что электропроводность высокомолекулярного соединения возрастает с удлинением в нем цепи сопряжения, мы обратились к разработке полимеризационного процесса не анилина, а его функционализированного производного и изучению физических и физико-химических свойств выделенных продуктов. В качестве мономера для окислительной полимеризации был привлечен синтезированный нами ранее 2-(1-метил-2-бутен-1-ил)анилин [19], в $о$-положении ароматического ядра которого содержится увеличивающий цепь сопряжения алкенильный заместитель.

Причина разнообразия молекулярного строения, морфологии и свойств продуктов окисления анилина связана с существованием основных реагентов: мономера и растущей цепи в непротонированной и протонированной формах и наличием двух механизмов окисления: цепной реакции электрофильного замещения и механизма рекомбинации катион-радикальных центров. Вклад обеих реакций зависит от состояния протонирования реагентов, следовательно, от $\mathrm{pH}$ реакционной среды.

3.1. Синтез производных полианилина. Гомополимеризация 2-(1-метил-2-бутен-1-ил)анилина была проведена с помощью его окисления, в результате чего в водных растворах кислот имело место образование темно-зеленого осадка полимера 1. В качестве окислителя чаще всего использовался персульфат аммония. Считается, что его применение приводит к образованию 
полимера со значительной молекулярной массой, показывающего высокую проводимость. Окисление анилина проводилось в кислой среде с использованием соляной кислоты при $\mathrm{pH}=0-2$ согласно схеме, приведенной на рис. 1.

Сополимеры производных анилина 2-4 синтезировали в различных мольных соотношениях $о$-толуидина и 2-(1-метил-2-бутен-1-ил)анилина по методикам, аналогичным синтезу гомополимера 1.

3.2. Исследование электрохимических свойств производных полианилинов.

3.2.1. Метод циклической вольтамперометрии. С целью проведения электрохимического исследования для всех синтезированных производных ПАНИ сняты вольтамперограммы, которые обнаруживают несколько анодных и катодных пиков. По их первым значениям определены потенциалы окисления и восстановления, которые, в свою очередь, соответствуют потенциалу ионизации и сродству к электрону полупроводниковых материалов.

На основании определенных окислительно-восстановительных характеристик производных ПАНИ рассчитаны энергия низшей свободной молекулярной орбитали (НСМО) из первого потенциала восстановления $\left(E_{\mathrm{red}}^{1}\right)$ и энергия высшей занятой молекулярной орбитали (ВЗМО) из первого потенциала окисления $\left(E_{\mathrm{ox}}^{1}\right)$ (табл. 1). Разность энергетических уровней НСМО-ВЗМО позволила оценить ширину запрещенной зоны исследуемых доноров $\left(E_{g}\right)$.

Среди изученных соединений наибольшее значение потенциала окисления и соответственно наименьший энергетический уровень ВЗМО отмечается для производного 1. Как следствие - увеличение значений напряжения холостого хода - одной из основных характеристик солнечных батарей, что обеспечивает более высокий к.п.д. преобразования света в них.

В сополимерах 2-4 с увеличением содержания o-толуидинового сомономера наблюдается понижение энергетических уровней ВЗМО, с одной стороны, с другой - сужение ширины запрещенной зоны сополимеров, что при конструировании органических солнечных батарей приводит к повышению значений тока короткого замыкания.

3.2.2. Температурная зависимость проводимости полимерных пленок. Измерены зависимости проводимости пленок различных форм полианилинов от температуры. Проведены измерения для растворимых форм модифицированного гомополимера ПАНИ - поли-2-(1-метил-2-бутен-1-ил)анилина и его сополимеров с $о$-толуидином в разных мольных соотношениях. Температурные измерения проводимости пленок $G$ в интервале $300-450 \mathrm{~K}$ показали экспоненциальный характер зависимости $G$ от температуры $T$

$$
G=G_{0} \exp \left(-\frac{\Delta E}{2 k T}\right) .
$$

В координатах $\ln G-1000 / T$ экспериментальные точки в пределах погрешности укладываются на прямые (рис. 2).

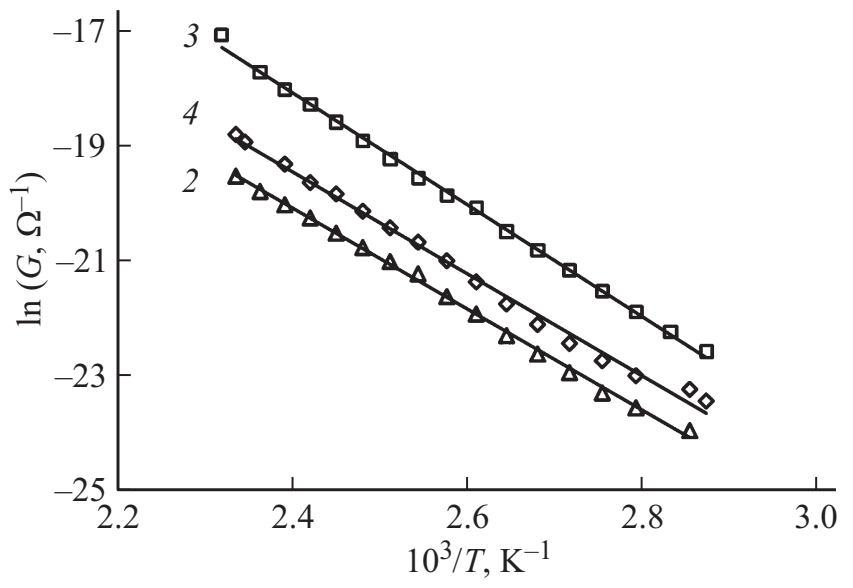

Рис. 2. Зависимость проводимости от обратной температуры для пленок сополимеров (о-толуидин с 2-(1-метил-2-бутен-1ил)анилином) в различных мольных соотношениях: 1:3 (2), $1: 1(3), 3: 1(4)$.

Величину $\Delta E$ (табл. 1) можно интерпретировать как интервал между ВЗМО и НСМО (аналог запрещенной зоны) в полупроводниковых полимерных пленках.

Из данных таблицы следует, что ширина запрещенной зоны меняется от образца к образцу и находится в интервале $1.39-1.66 \mathrm{eV}$. Зависимость ширины запрещенной зоны от мольного соотношения сополимеров, используемых для получения тонких пленок, является исключительно важным свойством для их практического применения в разнообразных электронных устройствах. На основе исследованных полимерных соединений возможна последующая разработка электронных устройств, аналогичных устройствам на неорганических гетероструктурах $\mathrm{Ga}_{1-x} \mathrm{Al}_{x} \mathrm{As}$.

Чтобы понять, каким образом осуществляется транспорт заряда через границу металл-полимер, были измерены температурные зависимости тока $I$ через пленочную структуру. В координатах $\ln I / T^{2}-1000 / T$ графические зависимости в пределах погрешности измерений хорошо аппроксимируются прямыми (рис. 3) в соответствии с формулой

$$
J=A^{*} \cdot T^{2} \exp \left[\frac{-e\left(\varphi_{\mathrm{B}}-\sqrt{e F / 4 \pi \varepsilon \varepsilon_{0}}\right)}{k T}\right],
$$

где $J$ - плотность тока, $A^{*}$ - постоянная Ричардсона, $e$ - заряд электрона, $\varphi_{\mathrm{B}}-$ высота барьера, $F-$ напряженность электрического поля, $\varepsilon$ - диэлектрическая проницаемость образца, $\varepsilon_{0}-$ электрическая постоянная, $k-$ постоянная Больцмана, $T-$ температура. Плотность тока определяется как $J=I / S$, где $S$ - площадь сечения пленки, которая не меняется, поэтому при построении графиков вместо плотности тока можно использовать значения тока через образец. Согласно формуле (1), тангенсы угла наклона прямых участков пропорциональны высоте барьера Шоттки $\varphi_{\mathrm{B}}$. Полученные в результате расчетов значения приведены в табл. 1. 
Таблица 1. Электрохимические характеристики синтезированных производных ПАНИ

\begin{tabular}{c|c|c|c|c|c|c|c|}
\hline \multirow{2}{*}{ № } & \multirow{2}{*}{$E_{\text {ox }}^{1}, \mathrm{~V}$} & \multirow{2}{*}{$E_{\text {red }}^{1}, \mathrm{~V}$} & $E_{\mathrm{B} 3 \mathrm{MO}}, \mathrm{eV}^{*}$ & \multirow{2}{*}{$E_{\mathrm{HCMO}}, \mathrm{eV}^{* *}$} & \multicolumn{2}{|c|}{$E_{g}, \mathrm{eV}$} & \multirow{2}{*}{$\varphi_{\mathrm{B}}, \mathrm{eV}$} \\
\cline { 5 - 7 } & & & & & ЦВА & ЭФ \\
\hline 1 & 0.54 & -1.07 & -5.31 & -3.73 & 1.61 & 1.55 & 0.71 \\
2 & 0.49 & -1.11 & -5.29 & -3.69 & 1.60 & 1.52 & 0.69 \\
3 & 0.44 & -1.13 & -5.24 & -3.67 & 1.57 & 1.68 & 0.77 \\
4 & 0.29 & -1.25 & -5.09 & -3.55 & 1.54 & 1.53 & 0.70
\end{tabular}

Пр и ме чан и е. ${ }^{*} E_{\mathrm{HCMO}}=-\left(E_{\mathrm{red}}^{1}+4.8\right)(\mathrm{eV}),{ }^{* *} E_{\mathrm{B} 3 \mathrm{MO}}=-\left(E_{\mathrm{ox}}^{1}+4.8\right)(\mathrm{eV})$. ЦВА - циклическая вольтамперометрия. ЭФ - электрофизические измерения.

Анализ полученных зависимостей позволяет предположить, что основным механизмом переноса носителей заряда через границу металлической подложки и полимерной пленки является термоэлектронная эмиссия Шоттки, которая определяет транспорт носителей в диапазоне температур $300-450 \mathrm{~K}$. Это подтверждает вывод о том, что переход носителя заряда через границу металл-полимер осуществляется в результате надбарьерного переноса. При этом высота барьера определяется разницей работы выхода металла и электронного сродства полимера. Например, для пленочных образцов из сополимеров 3 расчет по результатам электрофизических измерений дает величину $0.77 \mathrm{eV}$ (табл. 2). Учитывая работу выхода $\mathrm{Al} 4.26 \mathrm{eV}$ и электронное сродство полимера $3.5-3.6 \mathrm{eV}$, получаем $0.76-0.66 \mathrm{eV}$, то есть имеем величину, сопоставимую со значением, рассчитанным из модели Шоттки. Поскольку полевая добавка в формуле (1) составляет величину, не превышающую $0.1 \mathrm{eV}$, она не учитывалась. Таким образом, приведенные выше расчеты - еще одно свидетельство в пользу модели надбарьерного переноса на границе металл-полимер.

Полученные значения ВЗМО и НСМО свидетельствуют о том, что исследованные нами полианилины

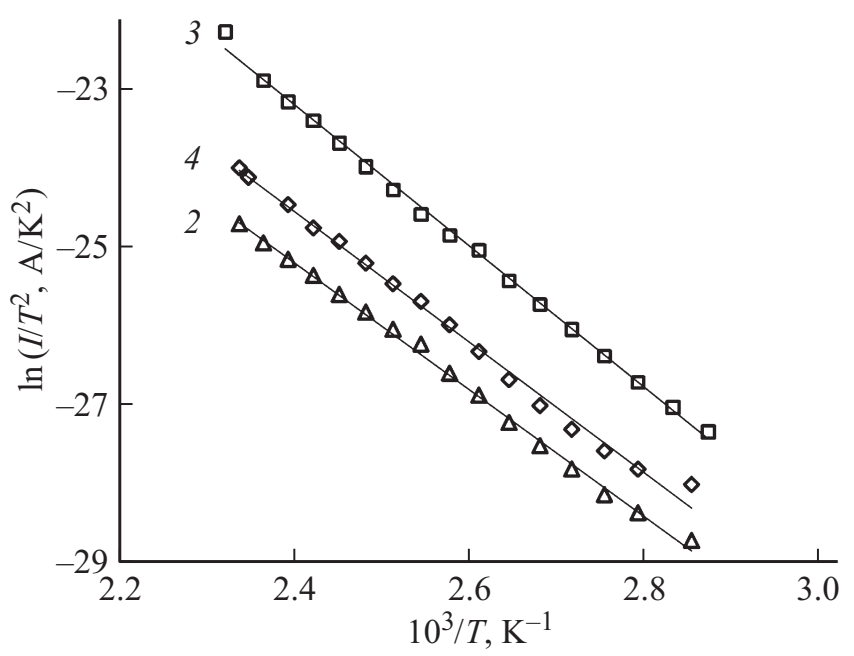

Рис. 3. Зависимость логарифма величины $I / T^{2}$ от обратной температуры для пленок сополимеров (о-толуидин с 2-(1-метил-2-бутен-1-ил)анилином) в различных мольных соотношениях: $1: 3(2), 1: 1(3), 3: 1(4)$. можно использовать для разработки новых органических солнечных элементов [20,21]. Ток короткого замыкания фотопреобразователя тесно связан с разницей в энергии между ВЗМО донора ПАНИ и НСМО акцептора. В качестве акцептора наиболее подходящим вариантом представляются метанофуллерены [22]. Эта разница определяет также напряжение холостого хода. Кроме того, ширина запрещенной зоны донора определяет минимальную энергию или максимальную длину волны поглощаемых фотонов. Для эффективного поглощения видимой части солнечного спектра ширина запрещенной зоны должна находиться в диапазоне $1.4-1.5 \mathrm{eV}$. Taким образом, гетеропереход поли-2-(1-метил-2-бутен-1ил)анилин/метанофуллерен, составленный из вновь синтезированных соединений, является оптимальным для изготовления лабораторного образца фотопреобразователя солнечной энергии.

3.3. Термогравиметрические исследования производных полианилинов. Группа термических методов анализа позволяет определить процессы, происходящие в веществе, что в дальнейшем находит отражение в изменении его эксплуатационных характеристик. Исследование процессов деструкции синтезированных полимеров необходимо как для прогнозирования поведения материалов на их основе в реальных условиях применения, так и для выяснения механизма деструкции с целью повышения термической стойкости веществ.

Изучение термической деструкции синтезированных производных полианилинов показало, что температура начала разложения $T_{\mathrm{H}}$, характеризующая начало изменения (снижения) массы образца полимера, составляет для гомополимера $1104^{\circ} \mathrm{C}$, т. е. такой полимер обладает относительно невысокой термической устойчивостью. Более высокие значения параметра $T_{\mathrm{H}}\left(140-150^{\circ} \mathrm{C}\right)$ демонстрируют сополимеры 3 и 4 (табл. 2).

Постепенное повышение температуры сопровождается монотонным снижением массы высокомолекулярного продукта. На полученных термограммах можно выделить две основные стадии разложения полимеров (табл. 2):

1) от 105 до $250^{\circ} \mathrm{C}$, изменение массы (со)полимера на этой стадии составляет $23-35 \%$;

2) от 250 до $600^{\circ} \mathrm{C}$, изменение массы полимера колеблется в пределах $13-21 \%$.

Разложение полимеров наиболее интенсивно проходит в области температур $150-290^{\circ} \mathrm{C}$, о чем свидетельству- 
Таблица 2. Параметры термостабильности функционализированных полианилинов

\begin{tabular}{c|c|c|c|c}
\hline № & $T_{\mathrm{H}},{ }^{\circ} \mathrm{C}$ & $\begin{array}{c}\text { Интервал } \\
\text { разложения, }\end{array}$ & $\Delta m, \%$ & $T_{\mathrm{m}},{ }^{\circ} \mathrm{C}$ \\
\hline 1 & 104 & $104-224$ & 22.9 & 168 \\
& \multirow{2}{*}{105} & $224-600$ & 13.5 & \\
& & $105-266$ & 26.7 & 226 \\
3 & \multirow{2}{*}{142} & $266-600$ & 16.4 & \\
& & $267-600$ & 26.8 & 229 \\
4 & \multirow{2}{*}{150} & $150-288$ & 35.1 & 231 \\
& & $288-600$ & 21.3 &
\end{tabular}

ет характерный пик на кривой ДТГ с максимумом при $T_{\mathrm{m}} \approx 170-230^{\circ} \mathrm{C}$ (для различных образцов) (табл. 2). При повышении температуры до $600^{\circ} \mathrm{C}$ происходит практически полное разложение полимеров: остаток продукта $\left(m_{600}\right)$ составляет $1-2 \%$. Интенсивное разложение полимеров при высоких температурах $\left(400^{\circ} \mathrm{C}\right.$ и выше) связано, по-видимому, с распадом $\mathrm{C}-\mathrm{C}$ связей макромолекулярной цепи, сопровождающим выделением газообразных продуктов.

\section{4. Выводы}

По результатам проделанной работы можно сделать следующие выводы:

1. На основе функционализированного мономерного анилина - (2-(1-метил-2-бутен-1-ил)анилин - впервые синтезированы и охарактеризованы растворимые электронодонорные проводящие (со)полимеры.

2. Показана хорошая корреляция результатов при изучении электрохимических свойств производных полианилина методами циклической вольтамперометрии и на основании температурной зависимости проводимости.

3. Полученный на основе 2-(1-метил-2-бутен-1-ил)анилина полимер имеет наименьший энергетический уровень ВЗМО, что предопределяет перспективность его использования в качестве донорного производного в активном слое при конструировании органических солнечных батарей.

\section{Список литературы}

[1] Э.Р. Блайт, Д. Блур. Электрические свойства полимеров. Физматлит, М. (2008). 375 с.

[2] N.E. Kazantseva. Magnetic particle-filled polymer microcomposites. In: Polymer Composites-Sabu Tomas. Willey-VCH, Weinheim. (2012). P. 613.

[3] И.И. Зятьков, А.И. Максимов, В.А. Мошников. Сенсоры на основе полевых транзисторов. СПБГЭТУ „ЛЭТИ“, СПб. (2002). $56 \mathrm{c}$.

[4] H. Bai, G. Shi. Sensors. 7, 267 (2007).

[5] В.Е. Боченков, В.Г. Сергеев. Успехи химии 76, 1084 (2007).

[6] V.V. Kondratiev, N.A. Pogulaichenko, E.G. Tolstopjatova, V.V. Malev. J. Solid State Electrochem. 15, 2383 (2011).
[7] T.J. Rivers, T.W. Hudson, C.E. Schmidt. Adv. Func. Mater. 12, 33 (2002).

[8] T.F. Otero, J.G. Martinez, J. Arias-Pardilla. Electrochim. Acta. 84, 112 (2012).

[9] J. Tarver, J.E. Yoo, T.J. Dennes, J.Schwartz, Y.L. Loo. Chem. Mater. 21, 280 (2009).

[10] В.Ф. Иванов, О.Л. Грибкова, К.В. Чеберяко, А.А. Некрасов, В.А. Тверской, А.В. Ванников. Электрохимия 40, 339 (2004).

[11] S. Bhadra, D. Khastgir, N.K. Singha, J.H. Lee. Prog. Polym. Sci. 34, 783 (2009).

[12] E.M. Geniès, A. Boyle, M. Lapkowski, C. Tsintavis. Synth. Met. 36, 139 (1990).

[13] H.J. Niu, M.L. Zhang, W.J. Zang, X.D. Bai, W. Wang. Mater. Sci. Technology 18, 796 (2010).

[14] D.D. Borole, U.R. Kapadi, P.P. Mahulikar, D.G. Hundiwale. Lett. 58, 3816 (2004).

[15] M.I. Florit. J. Electroanal. Chem. 408, 257 (1996).

[16] D.D. Borole, U.R. Kapadi, P.P. Mahulikar, D.G. Hundiwale. Mater. Lett. 60, 2447 (2006).

[17] И.Л. Кнунянц. Химический энциклопедический словарь. Сов. энциклопедия, М. (1983). 792 с.

[18] Л. Титце, Т. Айхер. Препаративная органическая химия. Реакции и синтезы в практикуме органической химии и научно-исследовательской лаборатории. Мир, М. (1999). $704 \mathrm{c}$.

[19] И.Б. Абдрахманов, А.Г. Мустафин, В.М. Шарафутдинов. Перегруппировка Кляйзена в ряду ароматических аминов. Гилем, Уфа. (2014). 168 с.

[20] R.B. Salikhov, Yu.N. Biglova, T.R. Salikhov, Yu.M. Yumaguzin. Nanoelectronics Optoelectron. 9, 792 (2015).

[21] Р.Б. Салихов, Ю.Н. Биглова, Ю.М. Юмагузин, Т.Р. Салихов, М.С. Мифтахов, А.Г. Мустафин. Письма в ЖТФ 39 (19), 25 (2013).

[22] Y.N. Biglova, A.F. Akbylatov, S.A. Torosyan, D.K. Susarova, A.G. Mustafin, M.S. Miftakhov. Physica B 458, 114 (2015). 